\title{
Functional and Chronic Anorectal and Pelvic Pain Disorders
}

\author{
Adil E. Bharucha, M.B.B.S, M.D. ${ }^{1}$ and Emanuel Trabuco, M.D. ${ }^{2}$ \\ 1 Division of Gastroenterology and Hepatology, College of Medicine, Mayo Clinic, Rochester, Minnesota, \\ USA
}

2 Department of Obstetrics and Gynecology, College of Medicine, Mayo Clinic, Rochester, Minnesota, USA

\section{Keywords}

anorectal pain; pelvic pain; levator ani syndrome; proctalgia fugax; interstitial cystitis; chronic prostatitis

\section{INTRODUCTION}

Several organic and functional disorders of the urinary bladder, reproductive tract, anorectum, and the pelvic floor musculature cause pelvic pain. This chapter describes functional disorders in which chronic pelvic and anorectal pain cannot be explained by a structural or other specified pathology. [1] Currently these functional disorders are classified into urogynecological conditions [i.e., chronic prostatitis/chronic pelvic pain syndrome (CP/CPPS) or cystitis/painful bladder syndrome (IC/PBS)], anorectal disorders (i.e., proctalgia fugax), and the levator ani syndrome. While these disorders are defined by predominant pain, they can be associated with functional disturbances (i.e., disordered voiding or defecation). Although this nomenclature suggests that these conditions are distinct, there is considerable overlap of their symptoms, which is perhaps inevitable because the urogenital tract and anorectum are in proximity and intimately related to the levator ani, because visceral discomfort is poorly localized, and because pelvic floor dysfunctions can impair urogenital and anorectal functioning. Indeed, these disorders have much in common. (Table 1) Not only is there overlap among urogynecological symptoms (e.g., chronic prostatitis, benign prostatic hypertrophy, and interstitial cystitis) [2] but also between pain in the urinary bladder (e.g., in interstitial cystitis) and sacrum, coccyx, and anus.[3]

Before symptom questionnaires were available, reports of these disorders were based on physician coded diagnoses, and diagnostic criteria probably varied among studies.[4] Although, validated symptom questionnaires for urinary and anorectal symptoms are available, (Table 2) diagnostic criteria, particularly for uro-gynecological conditions, are not established. These differences may partly explain why prevalence estimates vary across and even within studies.

Corresponding author for proof and reprints: Adil E. Bharucha, M.D. Clinical Enteric Neuroscience Translational and Epidemiological Research Program (C.E.N.T.E.R.) Mayo Clinic, 200 First St. S.W., Rochester, MN 55905 Telephone: 507-538-5854 Fax: 507-538-5820 E-mail: bharucha.adil@mayo.edu.

Publisher's Disclaimer: This is a PDF file of an unedited manuscript that has been accepted for publication. As a service to our customers we are providing this early version of the manuscript. The manuscript will undergo copyediting, typesetting, and review of the resulting proof before it is published in its final citable form. Please note that during the production process errors may be discovered which could affect the content, and all legal disclaimers that apply to the journal pertain. 


\section{FUNCTIONAL ANORECTAL PAIN}

Based on clinical features, the Rome III criteria recognize two forms of functional anorectal pain, i.e., levator ani syndrome and proctalgia fugax. In the levator ani syndrome, pain is generally prolonged (i.e., lasts for hours), is constant or frequent, and is characteristically dull. In proctalgia fugax, the pain is brief (i.e., lasting seconds to minutes), occurs infrequently (i.e., once a month or less often), and is relatively sharp. This classification system does not include coccygodynia, which refers to patients with pain and point tenderness of the coccyx, [5] as a separate entity. Most patients with rectal, anal, and sacral discomfort have levator rather than coccygeal tenderness.[6]

\section{LEVATOR ANI SYNDROME}

\section{Definition}

The levator ani syndrome is also called levator spasm,puborectalis syndrome, chronic proctalgia, pyriformis syndrome, and pelvic tension myalgia. The levator ani syndrome is characterized by relatively constant and/or frequent dull anorectal pain, often associated with tenderness to palpation of the levator ani but not urinary symptoms or an organic disease which can explain pain.

\section{Epidemiology}

The prevalence of symptoms compatible with levator ani syndrome in the general population is 6.6\%.[7] More than 50\% of affected people are aged 30-60 years,[6] and it is more common in women (7.4\% of all women) than in men (5.7\% of all men). [7] While the disability associated with levator ani syndrome can be significant, only $29 \%$ of people with levator pain had consulted a physician. In a postal survey of 5,430 adults, people with levator ani syndrome reported missing an average of 17.9 days from work or school in the past year, and $11.5 \%$ reported that they were currently too sick to work or go to school.[7] There are no published data on the frequency with which levator ani syndrome is encountered in medical practice.

\section{Pathophysiology}

Tenderness to palpation of pelvic floor muscles in chronic pelvic pain and levator ani syndrome may reflect visceral hyperalgesia and/or increased pelvic floor muscle tension, [8,9] the pathophysiology of which is unknown. Uncontrolled observations suggest that patients may have increased anal pressures or EMG activity.[10] Higher anal pressures may reflect increased external and/or internal anal sphincter tone. Inability to relax pelvic floor muscles suggests pelvic floor dysfunction. [9] It is unclear if the association between chronic pelvic pain and psychosocial distress on multiple domains (e.g., depression and anxiety, somatization, and obsessive-compulsive behavior)[11] reflects an underlying cause or an effect of pain.

\section{Clinical features}

The diagnosis is based on characteristic symptoms in the absence of anorectal and pelvic pathophysiology. The diagnostic criteria are as follows:[12]

Twelve weeks, which may not be consecutive, of:

1. Chronic or recurrent rectal pain or aching; and

2. Episodes last 20 minutes or longer; and

3. Other causes of rectal pain such as ischemia, inflammatory bowel disease, cryptitis, intramuscular abscess, fissure, hemorrhoids, prostatitis, and solitary rectal ulcer have been excluded. 
The pain is often described as a vague, dull ache, or pressure sensation high in the rectum. It is often worse with sitting than with standing or lying down. Physical examination may reveal overly contracted levator ani muscles and pelvic floor tenderness to palpation. For unknown reasons, tenderness is often asymmetric and more frequently affects the left than the right side. [6] The diagnosis is considered to be highly likely if patients have symptoms and abnormal physical signs and possible if patients have symptoms but not tenderness to levator palpation.

Patients with levator ani syndrome have significant elevations on the hypochondriasis, depression, and hysteria scales of the Minnesota Multiphasic Personality Inventory. This pattern, occurs in chronic pain patients, and is often referred to as the "neurotic triad."[13] Although clinical observations suggest that levator ani syndrome is frequently associated with an impaired quality of life, there is limited evidence in this regard.

\section{Treatment}

Appropriate testing (e.g., sigmoidoscopy, defecography, ultrasound, or pelvic MRI) to exclude other causes of pain (e.g., Crohn's disease, anal fissures), and to identify associated conditions (e.g., defecatory disorders) should be performed as necessary. There are no controlled studies of treatments for chronic intractable anorectal pain. Although uncontrolled studies suggest that electrogalvanic stimulation,[14-18] biofeedback training,[10,18-20] digital massage of the levator ani muscles,[20-22] and sitz baths[23] may be effective, management of chronic intractable anorectal pain can be a "frustrating endeavor".[18] Electrogalvanic stimulation improved pain in 10 of 27 patients in one study.[18] In a study of 316 patients with the levator syndrome, $68 \%$ percent of patients reported "good results" after a combination of massage, sitz baths, muscle relaxants, and diathermy (method unspecified).[6] The technique for levator massage is described later in this chapter. Biofeedback therapy improved pain but had variable effects on anal pressures.[10,20] Hot Sitz baths may alleviate pain not only by counterirritation but also because immersion in hot water may reduce anal pressures in patients with anorectal pain.[23] Ultrasound-guided injection of local anesthetics and/or alcohol for pelvic nerves (e.g., pudendal nerve) are of unproven efficacy.

If the patient's distress or other circumstances require that treatment be undertaken, the only advice that can be offered at present is to do no harm, that is, to select a treatment such as biofeedback which has no significant adverse consequences. Surgery should be avoided.

\section{PROCTALGIA FUGAX}

\section{Definition}

Proctalgia fugax is defined by sudden, severe intermittent pain in the anal area lasting several seconds or minutes in the absence of an organic disorder to explain pain.[12]

\section{Epidemiology}

The prevalence of proctalgia fugax has been difficult to determine because sufferers tend not to report episodes to their physician except in the most severe cases.[24] The estimated prevalence ranges from 8\%[7] to $18 \%$ [24] and is comparable in men and women. Symptoms rarely begin before puberty.

In the U.S. Householder Study,[7] subjects with proctalgia fugax missed an average of 12.8 days from work or school in the past year, and $8.4 \%$ of them reported that they were currently too ill to work or attend school. However, it is unknown if the reported disability was the result of proctalgia fugax, which seems unlikely, or other disorders in these patients. 


\section{Pathophysiology}

The pathophysiology of proctalgia fugax is unclear and is entirely based on small case reports which observed increased myoelectric activity and anal resting pressure during episodes of proctalgia.[25,26] An uncontrolled study suggested that a majority of patients were perfectionistic, anxious, and/or hypochondriacal.[27] A hereditary form of proctalgia fugax associated with hypertrophy of the internal anal sphincter has also been reported.[28-30]

\section{Clinical features}

The diagnosis is based on characteristic symptoms in the absence of anorectal and pelvic pathophysiology. The criteria are as follows:[12]

Twelve weeks, which may not be consecutive, of:

1. Recurrent episodes of pain localized to the anus or lower rectum; and

2. Episodes last from seconds to minutes; and

3. There is no anorectal pain between episodes.

Attacks are generally not related to a specific triggering factor, are often precipitated by stressful life events or anxiety,[31] and may last from a few seconds to as long as 30 minutes. In a study of 148 patients of whom one-third had proctalgia fugax, the pain was localized to the anus in $90 \%$ of patients, occurred less than five times a year in 51\%, and lasted less than 1 min in $57 \%$. In most, activity was not interrupted by this pain and only $20 \%$ had ever reported it to a physician.[32] The pain has been described as cramping, gnawing, aching, or stabbing, may range from uncomfortable to unbearable, and radiates infrequently.[33]

\section{Management}

For a majority of patients, the episodes of pain are so brief that remedial treatment is impractical. Since symptoms occur infrequently, prevention is not feasible. Therefore, the emphasis is on reassurance and explanation. For patients with frequent symptoms, treatment may be considered. In a randomized control trial, the inhaled $\beta_{2}$ adrenergic agonist salbutamol was more effective than placebo for shortening the duration of episodes of proctalgia.[34] The $\alpha_{2}$-adrenergic agonist clonidine reduced symptoms in a single patient.[35] Coexistent psychological issues should be addressed with behavioral and/or pharmacological therapies.

\section{INTERSTITITAL CYSTITIS/PAINFUL BLADDER SYNDROME}

\section{Definition}

The definition of interstitial cystitis (IC) has evolved over time and remains a controversial area.[36] In 1987, the National Institute of Arthritis Diabetes, Digestive and Kidney Diseases workshop on IC proposed diagnostic criteria for clinical trials. [37] However, these criteria have since been found to be too restrictive for clinical research, and have been estimated to miss $60 \%$ of patients with painful bladder syndrome (PBS). An NIH panel update on the criteria for diagnosing PBS is pending.[38] Currently, the International Continence Society defines painful bladder syndrome as "suprapubic pain related to bladder filling, accompanied by other symptoms such as increased daytime and nighttime frequency, in the absence of infection or other pathology."[39] A subset of patients with PBS has IC, which is characterized by symptoms of PBS and vesical abnormalities, i.e., mucosal ulcerations (Hunner's ulcers), punctuate hemorrhages (glomerulations) after bladder hydrodistention, and an increased number of detrusor mast cells.[40] 


\section{Epidemiology}

Prevalence estimates vary from 1.8 per 100,000 for a physician-assigned diagnosis of IC in Olmsted County, Minnesota, to 450 per 100,000 for self-reported diagnosis of IC in the National Household Interview Survey.[36] In part, these differences may reflect the lack of consensus on what constitutes IC. IC is more common in women than in men.[41] The median age at first diagnosis was 45 years in women and 75 years in men.[41]

\section{Pathophysiology}

The pathophysiology is incompletely understood. It is thought that dysfunction of the normally impermeable urothelial lining leads to chronic diffusion of irritants across the urothelium, which in turn can cause neurogenic inflammation and mast cell activation.[42] Mast cell degranulation activates capsaicin-sensitive nerve fibers which release substance $\mathrm{P}$ and other neuropeptides that cause cell damage. Prolonged activation of mast cells and capsaicin sensitive nerve fibers can lead to neurogenic up-regulation, further damage bladder muscle, and cause bladder fibrosis. In 2004, Keay et al identified a glycosylated frizzled-related peptide inhibitor of cell proliferation that is secreted specifically by bladder epithelial cells from patients with IC.[43] This antiproliferative factor (APF) profoundly inhibits bladder cell proliferation by regulating cytokines and growth factors. However, this finding has not been confirmed by other groups, and there is no commercially-available assay for APF. Thus APF remains an attractive, yet elusive, biomarker for IC.[44]

\section{Clinical Features}

A comprehensive literature review observed that $63-92 \%$ of patients with interstitial cystitis reported suprapublic pain upon bladder filling that was relieved by urination.[45] Patients may also have pain at other sites (i.e., urethra, vagina, perineum, groin, or low back) and other urinary symptoms (i.e., urinary urgency, frequency, and nocturia).

In a large prospective cohort of patients with IC, the average symptom duration was 8 years. [46] A case control study observed that women with interstitial cystitis had significantly more pelvic surgeries than controls.[47] Anxiety and depression, dysmenorrhea, and irritable bowel syndrome are common comorbid conditions. However, in one study, the prevalence of these conditions was not significantly higher in patients than in controls.[9]

In addition to pelvic floor tenderness, patients may also have palpation-induced abdominal tenderness, pelvic asymmetry, and pelvic floor dysfunctions which may be manifest by an inability to maintain pelvic relaxation.[8,9]

\section{Diagnostic Tests}

Diagnostic testing (i.e., cystoscopy, urine cytology, and possibly urologic imaging) need to be tailored to each individual patient: patients with symptoms of detrusor overactivity who fail anticholinergic therapy, patients with symptoms of urinary infections with negative cultures, or patients with microscopic hematuria need to undergo further workup.[48] When IC is suspected, cystoscopic evaluation should include hydrodistension to assess for glomerulations (e.g., submucosal petechial hemorrhages) and Hunner's ulcers, and to assess bladder capacity. Assessing permeability with intravesical potassium is prone to false positive and negative results and is not recommended for diagnosing IC.[49-51]

\section{Differential Diagnosis}

Chronic pelvic pain is the most common symptom associated with endometriosis. In an international study of 1000 patients, pelvic pain (68\%), dysmenorrhea (79\%), and dyspareunia $(45 \%)$ were the commonest presenting symptoms of endometriosis.[45,52] Endometriosis is 
also associated with urinary symptoms and both conditions may coexist.[45] The response to hormonal treatment or lack thereof is a poor predictor of endometriosis and a laparoscopy with biopsy of suspected lesions is necessary for diagnosing endometriosis.[53] Cystoscopic findings favor a diagnosis of IC.

There is considerable symptom (i.e., urgency, frequency, and nocturia) overlap between overactive bladder and interstitial cystitis. Although these conditions may be distinguished by the presence of pelvic pain and dyspareunia in IC and urinary incontinence in overactive bladder syndrome,[45] the possibility of IC should be considered in patients with refractory overactive bladder.[54] Urodynamics evaluation can aid in distinguishing OAB from PBS. Patients with $\mathrm{OAB}$ may have detrusor contractions during filling cystometry, whereas patients with PBS tend to have stable detrusor activity with hypersensitivity during distention.

Patients with vuvlodynia generally report vulvar burning and dyspareunia but not urinary symptoms.[45]

\section{Management}

Collaboration between urologists, gynecologists, and physical therapists is essential in identifying the specific cause of pelvic pain and effectively treating these women. There are three primary treatment modalities for PBS; i.e., pharmacologic, bladder instillation, and physical therapy. For patients with refractory PBS symptoms, minimally invasive therapies (sacral nerve stimulation, vesical injection of botulinum toxin A, and transurethral fulguration/ resection of bladder lesions) and definitive surgical options (trigone sparing and non-sparing cystectomy with substitution enteroplasty) are available. Pharmacologic agents include pentosan polysulfate sodium (PPS, Elmiron; a polysaccharide purported to decreased urothelial permeability), hydroxyzine (Atarax, an $\mathrm{H} 1$ receptor antagonist that inhibits mast cell activation), tricyclic antidepressants, and immunosuppressive agents (eg, azathioprine, cyclosporin, and methotrexate). Systematic reviews of the limited data on these interventions observed modest benefits of PPS, amitriptyline, and hydroxyzine compared to placebo.[55] Intravesical instillation is preferred with dimethyl sulfoxide (DMSO), Bacillus CalmetteGuérin vaccine, PPS and other polysaccharides. Two, small randomized cross over trials (DMSO vs placebo and DMSO vs BCG) have demonstrated a beneficial effect for DMSO instillation.[56,57] There is currently insufficient data to support the other installation agents. [58] Although bladder distension is commonly performed, there is limited data supporting its efficacy in PBS patients.[55] Since significant complications (eg, bladder rupture) have been reported, this maneuver should be used for diagnostic and not therapeutic purposes.[59] Intravaginal massage can be provided by Thiele's technique in which, the muscles (i.e., coccygeus, iliococcygeus, pubococcygeus, and obturator internus) are massaged with tolerable pressure from origin to insertion in the direction of the muscle fibers, approximately 10 to 15 times per session, lasting fewer than 5 minutes for each session.[22] In addition to massaging the entire muscle, trigger points can also be subjected to ischemic compression lasting 10 to 15 seconds. Two weeks after completing 10 sessions of therapy (i.e., 2 sessions per week for 5 weeks), patients reported improved pelvic pain, bladder urgency, muscle tenderness, and mental and physical components of quality of life in interstitial cystitis.[22] Moreover, this improvement was partly sustained at 4.5 months after therapy. In another study, $70 \%$ of patients reported moderate or marked improvement after manual therapy for pelvic floor trigger points and myofascial release.[60]

Sacral nerve stimulation and botulinum toxin A vesical injection may be effective for some patients with refractory IC.[61,62] Small case series suggest that appropriate patient selection is critical for maximizing the benefits of surgical intervention for IC.[63-65] For example, 32 out of 34 patients with classic IC had complete symptom resolution following cystectomy with enteroplasty compared to only 3 of 13 patients with nonulcer disease.[63,65] 


\section{CHRONIC PELVIC PAIN AND CHRONIC PROSTATITIS}

\section{Definition}

$\mathrm{CP} / \mathrm{CPPS}$ is characterized by chronic pain in the perineum, tip of the penis, suprapubic region or scrotum, which is often worsened with voiding or ejaculation, in the absence of an organic disorder. Chronic prostatitis/chronic pelvic pain syndrome (type 3 prostatitis) constitutes the vast majority (i.e., more than 90\%) of cases of prostatitis. The other categories include acute bacterial prostatitis (type 1), chronic bacterial prostatitis (type 2), and asymptomatic inflammatory prostatitis (type 4).

\section{Epidemiology}

The estimated prevalence ranges from 2\% to 10\%.[66-69] Patients with CP/CPPS account for up to $15 \%$ of urology office visits in Italy and approximately 2 million medical office visits per year in the USA alone.[40,46] The condition appears to affect men of all ages.

\section{Pathophysiology}

The pathophysiology of CP/CPPS is unknown. Many different theories and mechanisms have been proposed. Only $33 \%$ of patients with CP/CPPS have prostatic inflammation on biopsies. [70] The evidence for an ongoing acute infection is "weak"; the presence of white blood cells in the prostatic fluid is probably not a reliable marker of infection.[71] Similar to other chronic pain syndromes such as fibromyalgia, heightened responses to noxious heat stimuli, applied in this instance to the perineum, have been reported.[72] These findings have been considered to reflect central sensitization. Psychological factors are involved, psychologic stress is common,[73] and depressive symptoms predict a worse quality of life in men with CP/CPPS. [74]

\section{Clinical Features}

Among women with chronic pelvic pain, gynecological conditions (e.g., endometriosis, ovarian cysts), painful intercourse, and urinary urgency and frequency were more common than in age-matched controls. [9] In patients presenting for care, chronic pelvic pain is frequently severe and interferes with lifestyle.[9] Indeed, the sickness impact is similar to that for myocardial infarction and Crohn's disease.[75] Compared to age-matched controls, men with $\mathrm{CP} / \mathrm{CPPS}$ are more likely to have cardiovascular disease, neurologic disease, sinusitis, and anxiety or depression.[76]

\section{Diagnostic testing}

Testing to try and identify specific and hopefully treatable cause of pelvic pain should be performed. However in a majority of men, no such cause will be identified. In addition to history and physical examination (including digital rectal examination), urinalysis and urine cultures should be performed. A pre- and post-prostate massage urine is as sensitive and specific as the four-glass test for diagnosing chronic bacterial prostatitis.[77] Other tests for consideration, which are detailed elsewhere, include prostatic ultrasound, urethral swab, urodynamic studies, and prostate-specific antigen.

\section{Management}

Although the evidence is mixed, a four-to-six-week course of antibiotics in men with CP/CPPS is frequently prescribed.[71] Repeated courses of antibiotics are not advisable. Alpha-1 adrenergic antagonists may also be effective when used for at least three months or longer. Tricyclic antidepressants (e.g., nortriptyline beginning at $10 \mathrm{mg}$ a day and increasing gradually up to a maximum of 75 to $100 \mathrm{mg}$ daily if necessary) may ameliorate pain by inhibiting neuronal uptake of norepinephrine and serotonin and thereby modulating visceral hypersensitivity. 
Other agents that have been tried with variable benefit include finasteride and the antiinflammatory bioflavonoid quercetin.

Pelvic floor physical therapy not only improved overall symptoms but also improved sexual dysfunction.[78] Acupuncture has also been suggested.[79] Prostate-specific therapies such as microwave thermotherapy or transurethral needle ablation have limited efficacy.[80]

\section{Acknowledgements}

This study was supported in part by USPHS NIH Grant P01 DK068055, and by the Mayo CTSA grant M01-RR00585 from the National Institutes of Health in support of the Physiology Laboratory and Patient Care Cores.

\section{REFRERENCES}

1. Clemens JQ. Male and female pelvic pain disorders - is it all in their heads? J Urol 2008;179:813-4. [PubMed: 18221967]

2. Barry MJ, Link CL, McNaughton-Collins MF, McKinlay JB. Boston Area Community Health I. Overlap of different urological symptom complexes in a racially and ethnically diverse, communitybased population of men and women. BJU Int 2008;101(1):45-51. [PubMed: 17868419]

3. Lilius HG, Oravisto KJ, Valtonen EJ. Origin of pain in interstitial cystitis. Effect of ultrasound treatment on the concomitant levator ani spasm syndrome. Scand J Urol Nephrol 1973;7(2):150-2. [PubMed: 4759775]

4. Williams RE, Hartmann KE, Steege JF. Documenting the current definitions of chronic pelvic pain: implications for research. Obstet Gynecol 2004;103(4):686-91. [PubMed: 15051560]

5. Thiele GH. Coccygodynia: cause and treatment. Dis Colon Rectum 1963;6:422-36. [PubMed: 14082980]

6. Grant SR, Salvati EP, Rubin RJ. Levator syndrome: an analysis of 316 cases. Dis Colon Rectum 1975;18(2):161-3. [PubMed: 1120448]

7. Drossman DA, Li Z, Andruzzi E, Temple RD, Talley NJ, Thompson WG, et al. U.S. householder survey of functional gastrointestinal disorders. Prevalence, sociodemography, and health impact. Dig Dis Sci 1993;38(9):1569-80. [PubMed: 8359066]

8. Peters KM, Carrico DJ, Kalinowski SE, Ibrahim IA, Diokno AC. Prevalence of pelvic floor dysfunction in patients with interstitial cystitis. Urology 2007;70(1):16-8. [PubMed: 17656199]

9. Tu FF, Holt JJ, Gonzales J, Fitzgerald CM. Physical therapy evaluation of patients with chronic pelvic pain: a controlled study. Am J Obstet Gynecol 2008;198(3):272.e1-7. [PubMed: 18313447]

10. Grimaud JC, Bouvier M, Naudy B, Guien C, Salducci J. Manometric and radiologic investigations and biofeedback treatment of chronic idiopathic anal pain. Dis Colon Rectum 1991;34(8):690-5. [PubMed: 1855425]

11. Anderson RU, Orenberg EK, Chan CA, Morey A, Flores V. Psychometric profiles and hypothalamicpituitary-adrenal axis function in men with chronic prostatitis/chronic pelvic pain syndrome. [see comment]. J Urology 2008;179(3):956-60.

12. Bharucha AE, Wald A, Enck P, Rao S. Functional anorectal disorders. Gastroenterology 2006;130 (5):1510-8. [PubMed: 16678564]

13. Heymen S, Wexner SD, Gulledge AD. MMPI assessment of patients with functional bowel disorders. Dis Colon Rectum 1993;36(6):593-6. [PubMed: 8500378]

14. Sohn N, Weinstein MA, Robbins RD. The levator syndrome and its treatment with high-voltage electrogalvanic stimulation. Am J Surg 1982;144(5):580-2. [PubMed: 6182809]

15. Nicosia JF, Abcarian H. Levator syndrome. A treatment that works. Dis Colon Rectum 1985;28(6): 406-8. [PubMed: 3874049]

16. Billingham RP, Isler JT, Friend WG, Hostetler J. Treatment of levator syndrome using high-voltage electrogalvanic stimulation. Dis Colon Rectum 1987;30(8):584-7. [PubMed: 3497787]

17. Ware, JE, Jr. SF-36 health survey: Manual and interpretation guide. Boston: The Health Institute, New Englad Medical Center; 1993. 
18. Ger GC, Wexner SD, Jorge JM, Lee E, Amaranath LA, Heymen S, et al. Evaluation and treatment of chronic intractable rectal pain--a frustrating endeavor. Dis Colon Rectum 1993;36(2):139-45. [PubMed: 8425417]

19. Gilliland R, Heymen JS, Altomare DF, Vickers D, Wexner SD. Biofeedback for intractable rectal pain: outcome and predictors of success. Dis Colon Rectum 1997;40(2):190-6. [PubMed: 9075756]

20. Heah SM, Ho YH, Tan M, Leong AF. Biofeedback is effective treatment for levator ani syndrome. Dis Colon Rectum 1997;40(2):187-9. [PubMed: 9075755]

21. Thiele GH. Tonic spasm of the levator ani, coccygeus and piriformis muscle: Relationship to coccygodynia and pain in the region of the hip and down the leg. Trans Am Proctol Soc 1936;37:14555.

22. Oyama IA, Rejba A, Lukban JC, Fletcher E, Kellogg-Spadt S, Holzberg AS, et al. Modified Thiele massage as therapeutic intervention for female patients with interstitial cystitis and high-tone pelvic floor dysfunction. Urology 2004;64(5):862-5. [PubMed: 15533464]

23. Dodi G, Bogoni F, Infantino A, Pianon P, Mortellaro LM, Lise M. Hot or cold in anal pain? A study of the changes in internal anal sphincter pressure profiles. Dis Colon Rectum 1986;29(4):248-51. [PubMed: 3948615]

24. Thompson WG. Proctalgia fugax. Dig Dis Sci 1981;26(12):1121-4. [PubMed: 7030675]

25. Rao SS, Welcher KD, Happel J. Can biofeedback therapy improve anorectal function in fecal incontinence? Am J Gastroenterol 1996;91(11):2360-6. [PubMed: 8931418]

26. Eckardt VF, Dodt O, Kanzler G, Bernhard G. Anorectal function and morphology in patients with sporadic proctalgia fugax. Dis Colon Rectum 2004;39:755-62. [PubMed: 8674367]

27. Pilling LF, Swenson WM, Hill JR. The psychologic aspects of proctalgia fugax. Dis Colon Rectum 1965;8(5):372-6. [PubMed: 5830661]

28. Kamm MA, Hoyle CH, Burleigh DE, Law PJ, Swash M, Martin JE, et al. Hereditary internal anal sphincter myopathy causing proctalgia fugax and constipation. A newly identified condition. Gastroenterology 1991;100(3):805-10. [PubMed: 1993504]

29. Celik AF, Katsinelos P, Read NW, Khan MI, Donnelly TC. Hereditary proctalgia fugax and constipation: report of a second family. Gut 1995;36(4):581-4. [PubMed: 7737568]

30. Guy RJ, Kamm MA, Martin JE. Internal anal sphincter myopathy causing proctalgia fugax and constipation: further clinical and radiological characterization in a patient. Euro J Gastroenterol Hepatol 1997;9(2):221-4.

31. Karras JD, Angelo G. Proctalgia fugax. Clinical observations and a new diagnostic aid. Dis Colon Rectum 1963;6:130-4.

32. Thompson WG. Proctalgia fugax in patients with the irritable bowel, peptic ulcer, or inflammatory bowel disease. Am J Gastroenterol 1984;79(6):450-2. [PubMed: 6731418]

33. Perry WH. Proctalgia fugax: a clinical enigma. South Med J 1988;81:621-3. [PubMed: 3285494]

34. Eckardt VF, Dodt O, Kanzler G, Bernhard G. Treatment of proctalgia fugax with salbutamol inhalation. Am J Gastroenterol 1996;91(4):686-9. [PubMed: 8677929]

35. Swain R. Oral clonidine for proctalgia fugax. Gut 1987;28(8):1039-40. [PubMed: 3666555]

36. Hanno PM. Re-imagining interstitial cystitis. Urol Clin North Am 2008;35(1):91-9. vii. [PubMed: 18061027]

37. Gillenwater JY, Wein AJ. Summary of the National Institute of Arthritis, Diabetes, Digestive and Kidney Diseases Workshop on Interstitial Cystitis, National Institutes of Health, Bethesda, Maryland, August 28-29, 1987. J Urol 1988;140(1):203-6. [PubMed: 3379688]

38. Hanno PM, Landis JR, Matthews-Cook Y, Kusek J, Nyberg L Jr. The diagnosis of interstitial cystitis revisited: lessons learned from the National Institutes of Health Interstitial Cystitis Database study. J Urol 1999;161(2):553-7. [PubMed: 9915447]

39. Clemens JQ, Link CL, Eggers PW, Kusek JW, Nyberg LM Jr, McKinlay JB, et al. Prevalence of painful bladder symptoms and effect on quality of life in black, Hispanic and white men and women. J Urol 2007;177(4):1390-4. [PubMed: 17382739]

40. Bartoletti R, Cai T, Mondaini N, Dinelli N, Pinzi N, Pavone C, et al. Prevalence, incidence estimation, risk factors and characterization of chronic prostatitis/chronic pelvic pain syndrome in urological 
hospital outpatients in Italy: results of a multicenter case-control observational study. J Urol 2007;178 (6):2411-5. [PubMed: 17937946]discussion 5

41. Roberts RO, Bergstralh EJ, Bass SE, Lightner DJ, Lieber MM, Jacobsen SJ. Incidence of physiciandiagnosed interstitial cystitis in Olmsted County: a community-based study. BJU Int 2003;91(3): 181-5. [PubMed: 12581000]

42. Macdiarmid SA, Sand PK. Diagnosis of interstitial cystitis/painful bladder syndrome in patients with overactive bladder symptoms. Rev Urol 2007;9(1):9-16. [PubMed: 17396167]

43. Keay SK, Szekely Z, Conrads TP, Veenstra TD, Barchi JJ Jr, Zhang C-O, et al. An antiproliferative factor from interstitial cystitis patients is a frizzled 8 protein-related sialoglycopeptide. [see comment]. Proc Natl Acad Sci U S A 2004;101(32):11803-8. [PubMed: 15282374]

44. Graham E, Chai TC. Dysfunction of bladder urothelium and bladder urothelial cells in interstitial cystitis. Cur Urol Rep 2006;7:440-6.

45. Bogart LM, Berry SH, Clemens JQ. Symptoms of interstitial cystitis, painful bladder syndrome and similar diseases in women: a systematic review.[see comment][erratum appears in J Urol. 2007 Jun; 177(6):2402]. J Urol 2007;177(2):450-6. [PubMed: 17222607]

46. Propert KJ, Schaeffer AJ, Brensinger CM, Kusek JW, Nyberg LM, Landis JR. A prospective study of interstitial cystitis: results of longitudinal followup of the interstitial cystitis data base cohort. The Interstitial Cystitis Data Base Study Group. [see comment]. J Urol 2000;163(5):1434-9. [PubMed: 10751852]

47. Ingber M, Peters K, Killinger K, Carrico D, Ibrahim I, Diokno A. Dilemmas in diagnosing pelvic pain: multiple pelvic surgeries common in women with interstitial cystitis. Int Urogynecol J 2008;19:341-5.

48. Butrick CW. Interstitial cystitis and chronic pelvic pain: new insights in neuropathology, diagnosis, and treatment. Clin Obstet Gynecol 2003;46(4):811-23. [PubMed: 14595223]

49. Gregoire M, Liandier F, Naud A, Lacombe L, Fradet Y. Does the potassium stimulation test predict cystometric, cystoscopic outcome in interstitial cystitis? J Urol 2002;168(2):556-7. [PubMed: 12131308]

50. Parsons CL, Dell J, Stanford EJ, Bullen M, Kahn BS, Willems JJ. The prevalence of interstitial cystitis in gynecologic patients with pelvic pain, as detected by intravesical potassium sensitivity. Am J Obstet Gynecol 2002;187(5):1395-400. [PubMed: 12439537]

51. Kuo H-C. Urodynamic study and potassium sensitivity test for women with frequency-urgency syndrome and interstitial cystitis. Urol Int 2003;71(1):61-5. [PubMed: 12845263]

52. Sinaii N, Plumb K, Cotton L, Lambert A, Kennedy S, Zondervan K, et al. Differences in characteristics among 1,000 women with endometriosis based on extent of disease. Fertil Steril 2008;89(3):53845. [PubMed: 17498711]

53. Jenkins TR, Liu CY, White J. Does response to hormonal therapy predict presence or absence of endometriosis? J Minim Invasive Gynecol 2008;15(1):82-6. [PubMed: 18262150]

54. MacDiarmid SA, Sand PK. Diagnosis of interstitial cystitis/Painful bladder syndrome in patients with overactive bladder symptoms. Rev Urol 2007;9(1):9-16. [PubMed: 17396167]

55. Fall M, Oberpenning F, Peeker R. Treatment of Bladder Pain Syndrome/Interstitial Cystitis 2008: Can We Make Evidence-Based Decisions? Eur Urol. 200810.1016/j.eururo.2008.03.086[Epub ahead of print]

56. Perez-Marrero R, Emerson LE, Feltis JT. A controlled study of dimethyl sulfoxide in interstitial cystitis. J Urol 1988;140(1):36-9. [PubMed: 3288775]

57. Peeker R, Haghsheno MA, Holmang S, Fall M. Intravesical bacillus Calmette-Guerin and dimethyl sulfoxide for treatment of classic and nonulcer interstitial cystitis: a prospective, randomized doubleblind study. J Urol 2000;164(6):1912-5. [PubMed: 11061879]discussion 5-6

58. Dimitrakov J, Kroenke K, Steers WD, Berde C, Zurakowski D, Freeman MR, et al. Pharmacologic management of painful bladder syndrome/interstitial cystitis: a systematic review. Arch Intern Med 2007;167(18):1922-9. [PubMed: 17923590]

59. Badenoch AW. Chronic interstitial cystitis. Brit J Urol 1971;43(6):718-21. [PubMed: 5159574]

60. Weiss JM. Pelvic floor myofascial trigger points: manual therapy for interstitial cystitis and the urgency-frequency syndrome. J Urol 2001;166(6):2226-31. [PubMed: 11696740] 
61. Smith CP, Radziszewski P, Borkowski A, Somogyi GT, Boone TB, Chancellor MB. Botulinum toxin a has antinociceptive effects in treating interstitial cystitis. Urology 2004;64(5):871-5. [PubMed: 15533466]discussion 5

62. Hill JR, Isom-Batz G, Panagopoulos G, Zakariasen K, Kavaler E. Patient perceived outcomes of treatments used for interstitial cystitis. Urology 2008;71(1):62-6. [PubMed: 18242366]

63. Peeker R, Aldenborg F, Fall M. The treatment of interstitial cystitis with supratrigonal cystectomy and ileocystoplasty: difference in outcome between classic and nonulcer disease. J Urol 1998;159 (5):1479-82. [PubMed: 9554337]

64. Nielsen KK, Kromann-Andersen B, Steven K, Hald T. Failure of combined supratrigonal cystectomy and Mainz ileocecocystoplasty in intractable interstitial cystitis: is histology and mast cell count a reliable predictor for the outcome of surgery? J Urol 1990;144(2 Pt 1):255-8. [PubMed: 2374189] discussion 8-9

65. Rossberger J, Fall M, Jonsson O, Peeker R. Long-term results of reconstructive surgery in patients with bladder pain syndrome/interstitial cystitis: subtyping is imperative. Urology 2007;70(4):63842. [PubMed: 17991529]

66. Nickel JC, Downey J, Hunter D, Clark J. Prevalence of prostatitis-like symptoms in a population based study using the National Institutes of Health chronic prostatitis symptom index. J Urol 2001;165(3):842-5. [PubMed: 11176483]

67. Roberts RO, Jacobson DJ, Girman CJ, Rhodes T, Lieber MM, Jacobsen SJ. Prevalence of prostatitislike symptoms in a community based cohort of older men. J Urol 2002;168(6):2467-71. [PubMed: 12441942]

68. Roberts RO, Jacobson DJ, Girman CJ, Rhodes T, Lieber MM, Jacobsen SJ. Low agreement between previous physician diagnosed prostatitis and national institutes of health chronic prostatitis symptom index pain measures. J Urol 2004;171(1):279-83. [PubMed: 14665894]

69. Hu JC, Link CL, McNaughton-Collins M, Barry MJ, McKinlay JB. The association of abuse and symptoms suggestive of chronic prostatitis/chronic pelvic pain syndrome: results from the Boston Area Community Health survey. J Gen Intern Med 2007;22(11):1532-7. [PubMed: 17763912]

70. True LD, Berger RE, Rothman I, Ross SO, Krieger JN. Prostate histopathology and the chronic prostatitis/chronic pelvic pain syndrome: a prospective biopsy study. [see comment]. J Urol 1999;162 (6):2014-8. [PubMed: 10569559]

71. Pontari MA. Chronic prostatitis/chronic pelvic pain syndrome. Urol Clin N Am 2008;35(1):81-9. vi.

72. Yang CC, Lee JC, Kromm BG, Ciol MA, Berger RE. Pain sensitization in male chronic pelvic pain syndrome: why are symptoms so difficult to treat? J Urol 2003;170(3):823-6. [PubMed: 12913708] discussion 6-7

73. Mehik A, Hellstrom P, Sarpola A, Lukkarinen O, Jarvelin MR. Fears, sexual disturbances and personality features in men with prostatitis: a population-based cross-sectional study in Finland. BJU Int 2001;88(1):35-8. [PubMed: 11446842]

74. Tripp DA, Curtis Nickel J, Landis JR, Wang YL, Knauss JS, Group CS. Predictors of quality of life and pain in chronic prostatitis/chronic pelvic pain syndrome: findings from the National Institutes of Health Chronic Prostatitis Cohort Study. BJU Int 2004;94(9):1279-82. [PubMed: 15610105]

75. Wenninger K, Heiman JR, Rothman I, Berghuis JP, Berger RE. Sickness impact of chronic nonbacterial prostatitis and its correlates. J Urol 1996;155(3):965-8. [PubMed: 8583619]

76. Pontari MA, McNaughton-Collins M, O'Leary MP, Calhoun EA, Jang T, Kusek JW, et al. A casecontrol study of risk factors in men with chronic pelvic pain syndrome. BJU Int 2005;96(4):559-65. [PubMed: 16104910]

77. Nickel JC, Shoskes D, Wang Y, Alexander RB, Fowler JE Jr, Zeitlin S, et al. How does the premassage and post-massage 2-glass test compare to the Meares-Stamey 4-glass test in men with chronic prostatitis/chronic pelvic pain syndrome? J Urol 2006;176(1):119-24. [PubMed: 16753385]

78. Anderson RU, Wise D, Sawyer T, Chan CA. Sexual dysfunction in men with chronic prostatitis/ chronic pelvic pain syndrome: improvement after trigger point release and paradoxical relaxation training. J Urol 2006;176(4 Pt 1):1534-8. [PubMed: 16952676]discussion 8-9

79. Chen R, Nickel JC. Acupuncture ameliorates symptoms in men with chronic prostatitis/chronic pelvic pain syndrome.[see comment]. Urology 2003;61(6):1156-9. [PubMed: 12809886]discussion 9 
80. Zeitlin SI. Heat therapy in the treatment of prostatitis. Urology 2002;60(6 Suppl):38-40. [PubMed: 12521593]discussion 1

81. Barry MJ, Fowler FJ Jr, O'Leary MP, Bruskewitz RC, Holtgrewe HL, Mebust WK, et al. The American Urological Association symptom index for benign prostatic hyperplasia. The Measurement Committee of the American Urological Association. J Urol 1992;148(5):1549-57. [PubMed: 1279218]discussion 64

82. Litwin MS, McNaughton-Collins M, Fowler FJ Jr, Nickel JC, Calhoun EA, Pontari MA, et al. The National Institutes of Health chronic prostatitis symptom index: development and validation of a new outcome measure. Chronic Prostatitis Collaborative Research Network. J Urol 1999;162(2):369-75. [PubMed: 10411041]

83. O'Leary MP, Sant GR, Fowler FJ Jr, Whitmore KE, Spolarich-Kroll J. The interstitial cystitis symptom index and problem index. Urology 1997;49(5A Suppl):58-63. [PubMed: 9146003] 
Table 1

Cardinal Features of Chronic Functional Anorectal and Urogynecological Disorders

Disorders are diagnosed by symptoms, supplemented by objective findings in interstitial cystitis

Predominant symptom is discomfort or pain; patients may also have dysfunctional voiding or defecation

Frequently associated with impaired quality of life, anxiety, and depression

Pathophysiology is barely studied and poorly understood; visceral hypersensitivity and pelvic floor dysfunction may play a role

Therapy is guided by clinical features. Therapeutic approaches have not been rigorously tested in clinical trials 
Table 2

Symptom Questionnaires for Chronic Pelvic Disorders

\begin{tabular}{|c|c|}
\hline Condition & Questionnaire \\
\hline Lower urinary tract symptoms in men with benign prostatic hypertrophy & AUA Symptom Index (SI) [81] \\
\hline Men with chronic prostatitis/chronic pelvic pain syndrome (CP/CPPS) & $\begin{array}{l}\text { National Institutes of Health Chronic Prostatitis Symptom Index } \\
\text { (NIH-CPSI) [82] }\end{array}$ \\
\hline Interstitial cystitis and painful bladder syndrome (IC/PB1S) & Interstitial Cystitis Symptom Index [83] \\
\hline Functional anorectal pain & Rome III Questionnaire [12] \\
\hline
\end{tabular}

